\title{
STUDY OF PHASE TRANSFORMATIONS IN FERROELECTRICS BASED ON CALCIUM TITANATE
}

\author{
Kozlovskiy A.L. ${ }^{1,2^{\star}}$, Zdorovets M.V. ${ }^{1,2,3}$ \\ ${ }^{1}$ Institute of Nuclear Physics of the Kazakhstan Republic of, Almaty, Kazakhstan \\ 2L.N. Gumilyov Eurasian National University, Nur-Sultan, Kazakhstan, kozlovskiy.a@inp.kz \\ 3 Ural Federal University, Yekaterinburg, Russia
}

\begin{abstract}
The aim of this work is to study phase transformations kinetics in ferroelectrics based on calcium titanate. The relevance of this study is in the assessment of new methods for obtaining complex phase composition ferroelectrics, which have the potential for application in microelectronics, photocatalysis, and power engineering. The methods of scanning electron microscopy and X-ray diffraction were used as the main methods of analysis. Analysis of morphological features made it possible to establish the kinetics of changes not only in grain sizes, but also in their geometry. During the studies of phase transformations, the following dependence of the $\mathrm{TiO}_{2}$ - anatase/CaTi ${ }_{2} \mathrm{O}_{4} \rightarrow \mathrm{TiO}_{2}-$ anatase $/ \mathrm{CaTi}_{2} \mathrm{O}_{4} / \mathrm{CaTiO}{ }_{3} \rightarrow \mathrm{CaTiO}_{3} / \mathrm{TiO}_{2}$ - rutile type was established depending on the annealing temperature. At the same time, at a temperature of $1000^{\circ} \mathrm{C}$, a stable structure of ceramic with a perovskite-like structure of the $\mathrm{CaTiO}_{3}$ type and a high structural ordering degree (more than $92 \%)$ is formed.
\end{abstract}

Keywords: calcium titanate, phase transformations, perovskites, ferroelectrics, crystallinity degree.

\section{Introduction}

Today, one of the promising materials in microelectronics, photocatalysis and power engineering are ferroelectrics with a perovskite-like structure of the $\mathrm{ABO}_{3}$ type, where $\mathrm{A}-\mathrm{Ba}, \mathrm{Ca}, \mathrm{Sr}, \mathrm{B}-\mathrm{Ti}, \mathrm{Zr}, \mathrm{Fe}$, at.al. [1-5]. Interest in them is due to their semiconductor and ferroelectric properties, which make it possible to use them as capacitors, semiconductor devices, microwave resonators, photocatalysts, as well as the basis for creation of high-frequency electronics devices [6, 7]. A distinctive feature of titanates of barium, calcium and strontium are high dielectric constant, which open up broad prospects for research, as well as their practical application [8-10].

One of the important features affecting the properties of materials, as well as their practical application, is the structural ordering degree and the phase composition of ceramics, which directly depends on the conditions and methods of production. The choice of synthesis methods of ferroelectrics plays an important role on the structural ordering degree and phase composition [11-15]. In most cases, methods of hydrothermal synthesis or plasma sputtering with subsequent heat treatment are used to obtain these types of ceramics [15-25]. However, despite all the positive aspects of these methods, there is a number of limitations imposed on the obtained samples, primarily related to control of structural parameters, as well as the possibility of their variation and obtaining complex composition structures [25-30]. In recent years, alternative methods for production of ferroelectric ceramics with given properties are solid-phase synthesis methods combined with thermal isochronous annealing, which allow controlling the phase composition and crystallinity degree with high accuracy.

Based on the above, the purpose of this work is to study the kinetics of phase transformations in ferroelectrics based on calcium titanate obtained using the solid-phase synthesis method depending on the annealing temperature in the range of $200-1000^{\circ} \mathrm{C}$. The relevance of these works is due to the great potential for the applicability of these types of ceramics in microelectronics and photocatalysis.

\section{Experimental part}

As the initial salts, the following precursors were used: $\mathrm{CaCO}_{3}$ and $\mathrm{TiO}_{2}$ - anatase, manufactured by Sigma Aldrich (USA) with chemical purity of $99.95 \%$. The main method for producing ferroelectric ceramics was the method of solid-phase synthesis combined with thermal isochronous annealing at temperatures of $200-1000^{\circ} \mathrm{C}$ in a muffle furnace for 5 hours. The choice of the annealing time and 
temperatures is determined by the estimated data from the literature sources of the kinetics of phase transformations in titanates. After annealing, the resulting mixtures were cooled for 24 hours together with a muffle furnace until they completely cooled down and reached room temperature.

The assessment of the morphological features and geometric dimensions of the obtained ferroelectrics was carried out using scanning electron microscopy via Jeol 7500F, Jeol, Japan scanning electron microscope. The study of phase transformations was carried out using the X-ray diffraction method, by analyzing the obtained X-ray diffraction patterns in the Bregg-Brentano geometry in the angular range of $2 \theta=20-85^{\circ}$ with a step of $0.03^{\circ}$ and a spectrum set time at a point of $1 \mathrm{sec}$. Phase and structural parameters were determined using the program code DiffracEVA v.4.2. The phases were refined by comparing the obtained diffraction patterns with the PDF-2(2016) database. Phase selection was carried out when the coincidence probability of the registered diffraction maxima with the positions of the database values was more than $90 \%$. Determination of crystallinity degree was carried out by definement of the ratio of diffraction peak areas to background radiation area. This parameter allows assessing the structural ordering degree of the crystal structure depending on external factors, including thermal annealing.

\section{Results and discussion}

Figure 1 shows SEM images of synthesized ceramics depending on the annealing temperature, which reflect the kinetics of changes in the morphological features of the samples under study. As can be seen from the data presented, in the case of annealing temperatures of $200-400^{\circ} \mathrm{C}$ in the structure of ceramics, the presence of large cubic and diamond-shaped particles surrounded by small grains of a spherical or spherelike shape is observed. The presence of such particles is due to the grinding and phase formation processes, which have arisen as a result of mechanochemical synthesis. An increase in the annealing temperature to $600^{\circ} \mathrm{C}$ and above leads to the complete melting of large diamond-shaped structures with the formation of small spherical particles covered with a porous shell. At an annealing temperature of $1000^{\circ} \mathrm{C}$, particles grow larger with the formation of branched conglomerates, the size of which is several hundred nanometers. In this case, the formed conglomerates are also covered with a porous shell. This behavior of the morphological features and geometry of grains indicates a change in the phase composition as a result of thermal annealing, and the presence of several types of particles during low-temperature annealing indicates the presence of several phases in the structure of ceramics.

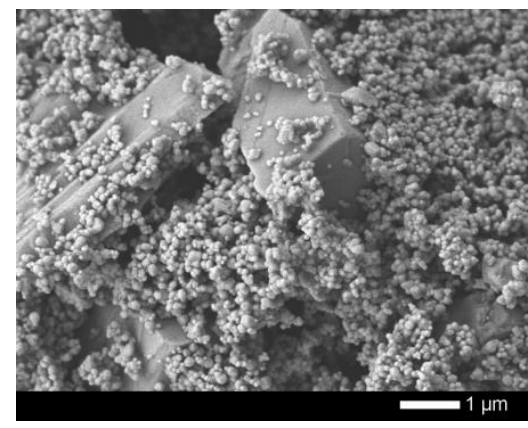

a)

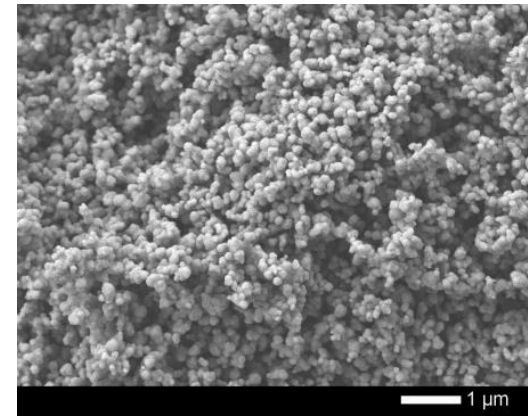

d)

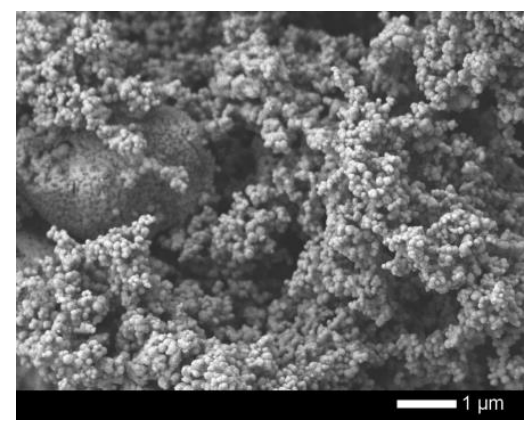

b)

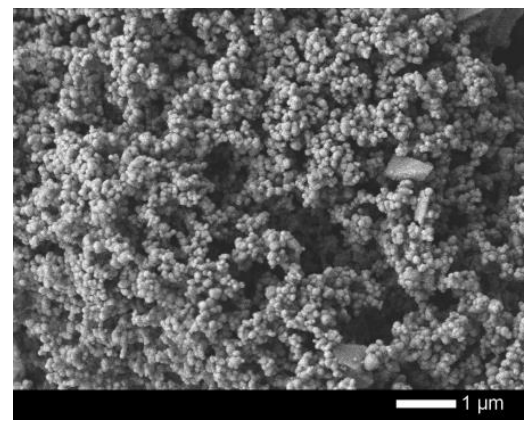

c)

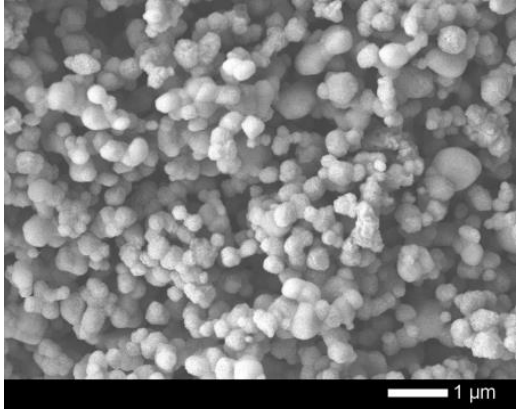

e)

Fig.1. SEM - images: a) $200^{\circ} \mathrm{C}$; b) $400^{\circ} \mathrm{C}$; c) $600^{\circ} \mathrm{C}$; d) $800^{\circ} \mathrm{C}$; e) $1000^{\circ} \mathrm{C}$ 
Figure 2 shows X-ray diffraction patterns of synthesized ceramics, reflecting phase transformations and the formation of a crystal structure depending on the annealing temperature. The general appearance of changes in diffraction patterns depending on the annealing temperature indicates the dynamics of change in phase composition of ceramics due to the formation of new phases at an annealing temperature above $600^{\circ} \mathrm{C}$. In the case of the ceramics annealing temperature of $200^{\circ} \mathrm{C}$, the phase composition, according to the applied full-profile analysis method for diffraction peaks evaluation, is characterized by the presence of two phases: the tetragonal phase of titanium dioxide $\left(\mathrm{TiO}_{2}\right)$ and the orthorhombic phase of $\mathrm{CaTi}_{2} \mathrm{O}_{4}$. At the same time, the shape of diffraction lines and their angular position indicate a large degree of structural distortions and deformations in the crystal lattice, the presence of which is due to mechano-chemical grinding processes.

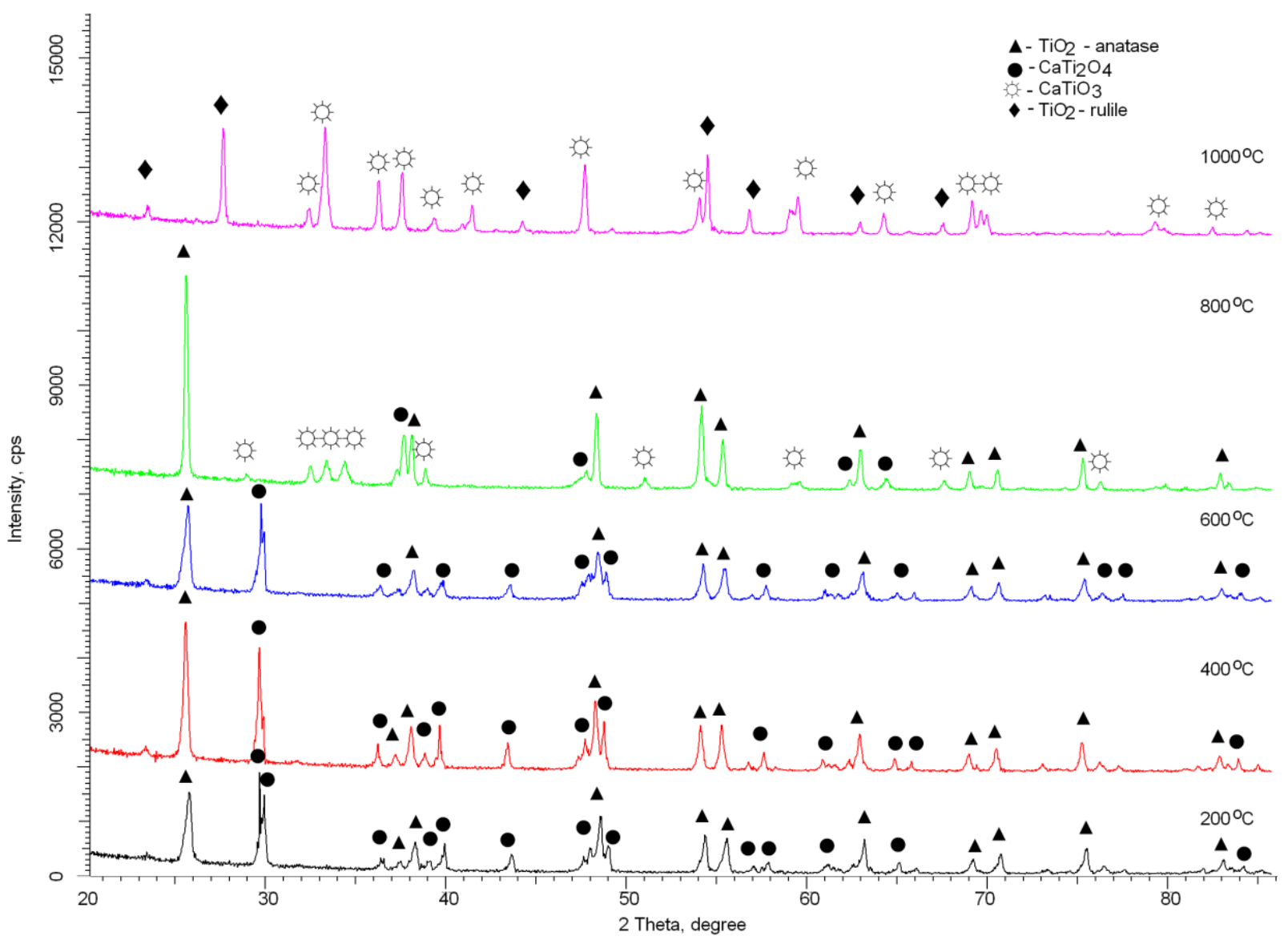

Fig.2. X-ray diffraction patterns of synthesized ceramics versus annealing temperature

At $400^{\circ} \mathrm{C}$ and $600^{\circ} \mathrm{C}$, the appearance of new phases has not been established, but there is an increase in structural ordering, which is evidenced by a change in the shape of diffraction lines and a decrease in their asymmetry. Also, an increase in the structural ordering degree is evidenced by a change in the crystallinity degree, the results of which are shown in Figure 3a. An increase in the crystallinity degree with an increase in the annealing temperature is also associated with a change in the content of $\mathrm{TiO}_{2}$ and $\mathrm{CaTi}_{2} \mathrm{O}_{4}$ phases in the ceramics structure, the results of which are shown in Figure $3 \mathrm{~b}$.

At annealing temperatures of 200 and $400^{\circ} \mathrm{C}$, the dominant phase in the structure of ceramics was the anatase $\mathrm{TiO}_{2}$ phase, the content of which was twice the content of the $\mathrm{CaTi}_{2} \mathrm{O}_{4}$ phase, which is known to be a metastable and transitional phase for the $\mathrm{CaTiO}_{3}$ phase. An increase in the annealing temperature from 400 to $600^{\circ} \mathrm{C}$ leads to the dominance of the $\mathrm{CaTi}_{2} \mathrm{O}_{4}$ phase, which indicates its ordering in the structure. At an annealing temperature of $800^{\circ} \mathrm{C}$, a phase transformation is observed with the formation of the orthorhombic $\mathrm{CaTiO}_{3}$ phase from the $\mathrm{CaTi}_{2} \mathrm{O}_{4}$ phase, as well as a decrease in the anatase phase contribution. This phase transformation is also accompanied by a sharp increase in the structural ordering degree and compaction of ceramics. A further increase in the annealing temperature to $1000^{\circ} \mathrm{C}$ leads to complete displacement of the anatase phase from the structure and its transformation into the rutile phase, the content of which is less than $10 \%$, as well as the complete transformation of the $\mathrm{CaTi}_{2} \mathrm{O}_{4} \rightarrow \mathrm{CaTiO}_{3}$ type. 
Thus, from the data presented, it can be concluded that at a temperature of $1000^{\circ} \mathrm{C}$, a stable structure of ceramics with a perovskite-like structure of the $\mathrm{CaTiO}_{3}$ type and a high structural ordering degree (more than $92 \%$ ) is formed. Also, based on the data obtained, it is possible to chart a diagram of phase transformations of the $\mathrm{TiO}_{2}-$ anatase $/ \mathrm{CaTi}_{2} \mathrm{O}_{4} \rightarrow \mathrm{TiO}_{2}-$ anatase $/ \mathrm{CaTi}_{2} \mathrm{O}_{4} / \mathrm{CaTiO}_{3} \rightarrow \mathrm{CaTiO}_{3} / \mathrm{TiO}_{2}-$ rutile type.

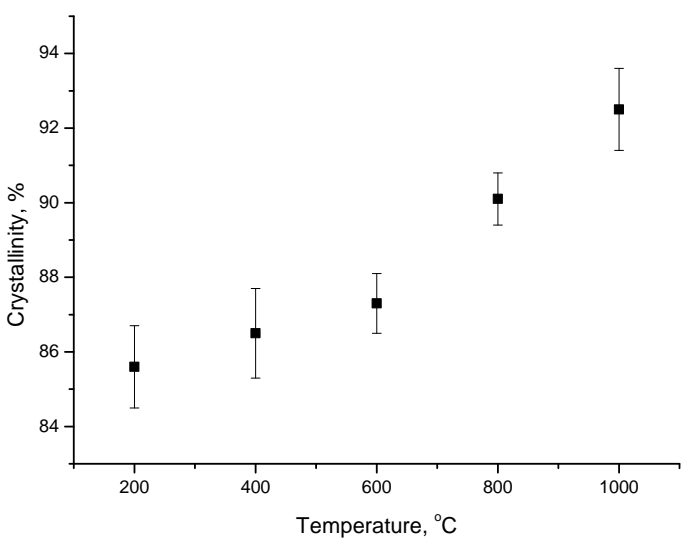

a)

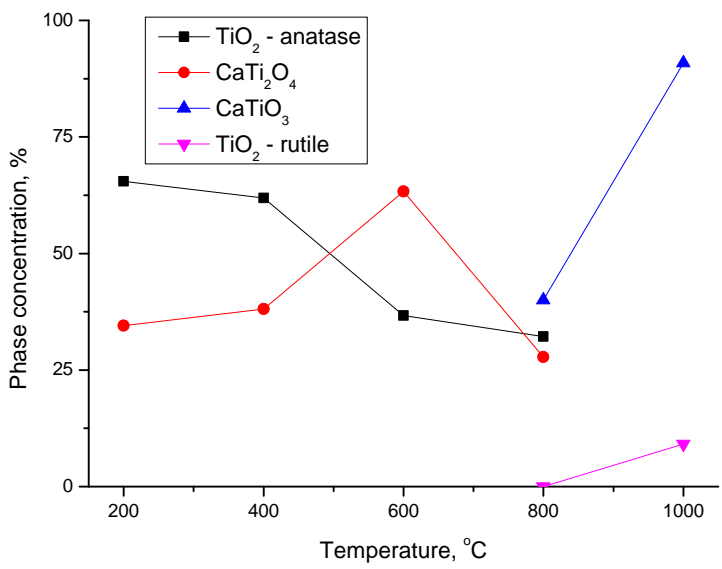

b)

Fig.3. a) Graph of the change in the crystallinity degree depending on the annealing temperature; b) Graph of changes in the phase composition of ceramics, obtained on the basis of a full-profile analysis of X-ray diffraction patterns.

Table 1 shows the results of determination of the crystal lattice parameters for each specific phase depending on the annealing temperature. As can be seen from the data presented, an increase in the annealing temperature, leading to an increase in the crystallinity degree, also leads to a decrease in the crystal lattice parameters and, consequently, to its compaction and to a decrease in the structure disorientation.

Table 1. Crystal lattice parameters data

\begin{tabular}{|c|c|c|c|c|}
\hline \multirow[b]{2}{*}{ Temperature, ${ }^{\circ} \mathrm{C}$} & \multicolumn{4}{|c|}{ Phase } \\
\hline & $\mathrm{TiO}_{2}-$ anatase & $\mathrm{CaTi}_{2} \mathrm{O}_{4}$ & $\mathrm{CaTiO}_{3}$ & $\mathrm{TiO}_{2}-$ rutile \\
\hline 200 & $\begin{array}{l}\mathrm{a}=3.74751 \AA \\
\mathrm{c}=9.45451 \AA \\
\mathrm{V}=132.78 \AA^{3}\end{array}$ & $\begin{array}{l}\mathrm{a}=9.69323 \AA \\
\mathrm{b}=9.98148 \AA \\
\mathrm{c}=3.14554 \AA \\
\mathrm{V}=304.34 \AA^{3}\end{array}$ & - & - \\
\hline 400 & $\begin{array}{l}\mathrm{a}=3.73355 \AA \\
\mathrm{c}=9.51198 \AA \\
\mathrm{V}=132.59 \AA^{3}\end{array}$ & $\begin{array}{c}\mathrm{a}=9.74455 \AA, \\
\mathrm{b}=10.04606 \AA, \\
\mathrm{c}=3.16836 \AA, \\
\mathrm{V}=310.16 \AA^{3}\end{array}$ & - & - \\
\hline 600 & $\begin{array}{l}\mathrm{a}=3.72550 \AA, \\
\mathrm{c}=9.49892 \AA, \\
\mathrm{V}=131.84 \AA^{3}\end{array}$ & $\begin{array}{c}\mathrm{a}=9.71589 \AA, \\
\mathrm{b}=10.00469 \AA, \\
\mathrm{c}=3.14910 \AA, \\
\mathrm{V}=306.11 \AA^{3}\end{array}$ & - & - \\
\hline 800 & $\begin{array}{l}\mathrm{a}=3.72624 \AA, \\
\mathrm{c}=9.47843 \AA, \\
\mathrm{V}=131.61 \AA^{3}\end{array}$ & $\begin{array}{c}\mathrm{a}=9.81305 \AA \\
\mathrm{b}=10.05373 \AA, \\
\mathrm{c}=3.16824 \AA, \\
\mathrm{V}=312.57 \AA^{3}\end{array}$ & $\begin{array}{l}\mathrm{a}=5.35063 \AA, \\
\mathrm{b}=5.42338 \AA, \\
\mathrm{c}=7.64146 \AA, \\
\mathrm{V}=221.74 \AA^{3}\end{array}$ & - \\
\hline 1000 & - & - & $\begin{array}{l}\mathrm{a}=5.32650 \AA, \\
\mathrm{b}=5.41168 \AA, \\
\mathrm{c}=7.62798 \AA, \\
\mathrm{V}=219.88 \AA^{3}\end{array}$ & $\begin{array}{c}\mathrm{a}=4.45210 \AA, \\
\mathrm{c}=2.94830 \AA, \\
\mathrm{V}=61.34 \AA^{3}\end{array}$ \\
\hline
\end{tabular}




\section{Conclusion}

In this work, the kinetics of phase transformations in calcium titanate ceramics of the $\mathrm{TiO}_{2}-$ anatase $/ \mathrm{CaTi}_{2} \mathrm{O}_{4} \rightarrow \mathrm{TiO}_{2}$ anatase $/ \mathrm{CaTi}_{2} \mathrm{O}_{4} / \mathrm{CaTiO}_{3} \rightarrow \mathrm{CaTiO}_{3} / \mathrm{TiO}_{2}$ - rutile type was estimated using scanning electron microscopy and $\mathrm{X}$-ray diffraction.

According to the data obtained, it was found that an increase in the annealing temperature leads not only to a change in the phase composition, but also in the structural ordering degree and volume of the crystal lattice, as well as to a decrease in the deformation of the structure. During the studies, it was found that at a temperature of $1000^{\circ} \mathrm{C}$, a stable structure of ceramics with a perovskite-like structure of the $\mathrm{CaTiO}_{3}$ type and a high structural ordering degree (more than $92 \%$ ) is formed. The chosen synthesis method allows obtaining ferroelectric ceramics of various phase compositions depending on the annealing temperature.

\section{Acknowledgments}

This research was funded by the Science Committee of the Ministry of Education and Science of the Republic of Kazakhstan (No. AP09259182).

\section{REFERENCES}

1 Yan, Yuxiang, et al. Design of ternary CaTiO3/g-C3N4/AgBr Z-scheme heterostructured photocatalysts and their application for dye photodegradation. Solid State Sciences, 2020, Vol. 100, pp.106102-106110.

2 Wang, Dawei, et al. Cold sintered CaTiO3-K2MoO4 microwave dielectric ceramics for integrated microstrip patch antennas. Applied Materials Today, 2020, Vol. 18, pp. 100519.

3 Kadam, A. R., et al. Thermoluminescence study and evaluation of trapping parameters CaTiO3: RE (RE= Eu3+, Dy3+) phosphor for TLD applications. Journal of Molecular Structure. 2021, Vol. 1225, pp. 129129.

4 Soltani, Tayyebeh, et al. Effect of transition metal oxide cocatalyst on the photocatalytic activity of Ag loaded CaTiO3 for $\mathrm{CO} 2$ reduction with water and water splitting. Applied Catalysis B: Environmental. 2021, Vol. 286, pp. 119899.

5 Dai, Fangxu, et al. ZnIn2S4 modified CaTiO3 nanocubes with enhanced photocatalytic hydrogen performance. International Journal of Hydrogen Energy. 2020, Vol 45.53, pp. 28783-28791.

6 Lanfredi S., et al. K-and $\mathrm{Cu}$-doped $\mathrm{CaTiO}$-based nanostructured hollow spheres as alternative catalysts to produce fatty acid ethyl esters as potential biodiesel. Applied Catalysis B: Environmental. 2020, Vol. 272, pp. 118986.

7 Zhang, Jiawei, et al. Enhanced energy storage performances of CaTiO3-based ceramic through A-site Sm3+ doping and A-site vacancy. Journal of the European Ceramic Society. 2021, Vol. 41.1, pp. 352-359.

8 Yatish, K. V., et al. Ochrocarpus longifolius assisted green synthesis of CaTiO3 nanoparticle for biodiesel production and its kinetic study. Renewable Energy. 2020, Vol. 147, pp. 310-321.

9 Chen, An-Nan, et al. Enhanced densification and dielectric properties of CaTiO3-0.3 NdAlO3 ceramics fabricated by direct coagulation casting. Journal of the European Ceramic Society. 2020, Vol. 40.4, pp. 1174-1180.

$10 \mathrm{Liu}, \mathrm{Hao}$, and Sufang Wu. In situ preparation of $\mathrm{CaTiO} 3$ and its effect on $\mathrm{CO} 2$ sorption performance of nano-CaOCaTiO3 adsorbent. Environmental Technology. 2020, pp. 1-11.

11 Pei, Jingyuan, et al. Effects of $\mathrm{Ca} / \mathrm{Ti}$ ratio on morphology control and photocatalytic activity of $\mathrm{CaTiO} / \mathrm{Ca}(\mathrm{OH}) 2$ composite photocatalyst. Materials Letters. 2020, Vol. 276, pp. 128229.

12 Rizwan, Muhammad, et al. Electronic and optical behaviour of lanthanum doped CaTiO3 perovskite. Materials Research Express. 2020, Vol.7.1, pp. 015920.

13 Zhang, Yanni, et al. Enhanced osteogenic differentiation of osteoblasts on $\mathrm{CaTiO} 3$ nanotube film. Colloids and Surfaces B: Biointerfaces. 2020, Vol.187, pp.110773.

14 Vasconcelos, S. J. T., et al. High thermal stability and colossal permittivity of novel solid solution LaFeO3/CaTiO3. Materials Chemistry and Physics. 2021, Vol.257, pp. 123239.

15 Yadi, Minoo, et al. CaTiO3/ $\alpha$-TCP coatings on CP-Ti prepared via electrospinning and pulsed laser treatment for invitro bone tissue engineering. Surface and Coatings Technology. 2020, Vol.401, pp. 126256.

16 Yin, Qian, et al. Enhancements of luminescent properties of CaTiO3: Dy3+, Pr3+ via doping $\mathrm{M}+=(\mathrm{Li}+, \mathrm{Na}+$, K+). Materials Letters. 2020, Vol.266, pp. 127488.

$17 \mathrm{Li}$, Shuiping, et al. Improvement of photovoltaic performance of perovskite solar cells by interface modification with CaTiO3. Journal of Power Sources. 2020, Vol.449, pp. 227504.

18 Zdorovets, M.V., Kozlovskiy A.L. The effect of lithium doping on the ferroelectric properties of LST ceramics. Ceramics International. 2020, Vol.46.10, pp. 14548-14557.

19 Dimza, Vilnis, et al. Effects of Mn doping on dielectric properties of ferroelectric relaxor PLZT ceramics. Current Applied Physics. 2017, Vol.17.2, pp. 169-173. 
20 Zdorovets, M.V., Kozlovskiy A.L. Study of the effect of La3+ doping on the properties of ceramics based on BaTiOx. Vacuum, 2019 Vol.168, pp. 108838.

21 Kozlovskiy A.L., et al. Synthesis, phase composition and structural and conductive properties of ferroelectric microparticles based on ATiOx (A= Ba, Ca, Sr). Ceramics International. 2019, Vol. 45.14, pp. 17236-17242.

22 Popov, A.I., Balanzat E. Low temperature X-ray luminescence of KNbO3 crystals. Nuclear Instruments and Methods in Physics Research Section B: Beam Interactions with Materials and Atoms. 2000, Vol.166, pp. 305-308.

23 Jumpatam, Jutapol, et al. Influences of Sr2+ Doping on Microstructure, Giant Dielectric Behavior, and Non-Ohmic Properties of CaCu3Ti4O12/CaTiO3 Ceramic Composites. Molecules. 2021, Vol.26.7, pp. 1994.

24 Klotins, E., Popov, A.I., Pankratov, V., Shirmane, L., Engers, D. Numerical evidences of polarization switching in PMN type relaxor ferroelectrics. Integrated Ferroelectrics, 2011, Vol. 123(1), pp. 32-39.

25 Grigorjeva, L., et al. Luminescence properties of KNbO3 crystals. Journal of luminescence. 1997, Vol.72, pp. 672674.

$26 \mathrm{Li}$, Runrun, et al. Thickness-dependent and tunable mechanical properties of CaTiO3 dielectric thin films determined by nanoindentation technique. Ceramics International. 2020, Vol. 46.14, pp. 22643-22649.

27 Abdul Kareem, et al. Effect of annealing temperatures on the structural and crystalline properties of CaTiO3 powder synthesized via conventional solid-state method. Materials Today: Proceedings. 2021, Vol.42, pp. 2674-2679.

28 Savchyn V.P., et al. Cathodo-luminescence characterization of polystyrene-BaZrO3 hybrid composites. Low Temperature Physics. 2016, Vol.42.7, pp. 597-600.

29 Yang, Liu, et al. Intense and recoverable piezoluminescence in Pr3+-activated CaTiO3 with centrosymmetric structure. Applied Physics Letters. 2021, Vol.118.5, pp. 053901.

30 Sasidharan, Sajesh, G. Jyothi, and K. G. Gopchandran. Solution combustion synthesis and luminescence dynamics of CaTiO3: Eu3+, Y3+ nanophosphors. Journal of Luminescence. 2021, Vol. 235, pp. 118048. 